\title{
Formulation and Prioritization of Sustainable New Product Design in Smart Glasses Development
}

\author{
Carman-Ka-Man Lee ${ }^{1,2}$ (D) Lucas Lui $^{1}$ and Yung-Po Tsang ${ }^{1, * \mathbb{D}}$ \\ 1 Department of Industrial and Systems Engineering, The Hong Kong Polytechnic University, Hung Hom, \\ Hong Kong, China; ckm.lee@polyu.edu.hk (C.-K.-M.L.); lucas.lui@connect.polyu.hk (L.L.) \\ 2 Laboratory for Artificial Intelligence in Design, Hong Kong, China \\ * Correspondence: yungpo.tsang@polyu.edu.hk
}

check for updates

Citation: Lee, C.-K.-M.; Lui, L.; Tsang, Y.-P. Formulation and Prioritization of Sustainable New Product Design in Smart Glasses Development. Sustainability 2021, 13, 10323. https://doi.org/10.3390/ su131810323

Academic Editors: Mike Tse,

Vincent Cho, C. H. Wu and

Roberto Cerchione

Received: 17 August 2021

Accepted: 13 September 2021

Published: 15 September 2021

Publisher's Note: MDPI stays neutral with regard to jurisdictional claims in published maps and institutional affiliations.

Copyright: (c) 2021 by the authors. Licensee MDPI, Basel, Switzerland. This article is an open access article distributed under the terms and conditions of the Creative Commons Attribution (CC BY) license (https:/ / creativecommons.org/licenses/by/ $4.0 /)$.

\begin{abstract}
Due to fierce competition in the global market, success in product innovation has always been challenging for most enterprises to be able to stand out in business values and product novelty. Typically, available technological features in the market are taken into consideration in the innovation process for differentiation from existing products. In order to enhance the likelihood of innovation success, project portfolio management (PPM) has recently been advocated to examine the supply chain performance of new product development (NPD) projects in terms of economic, social, and sustainable aspects. In this study, a two-stage methodology is proposed to formulate and select the most appropriate NPD project portfolio by means of multi-criteria decision-making (MCDM) approaches in probabilistic and group decision-making processes. In stage one, the available product features on the market are searched for and ranked to indicate a number of potential NPD projects. In stage two, such projects are evaluated by the sustainable supply chain operation reference (SustainableSCOR) model to select the most sustainable NPD project for product development. Moreover, a case study of developing augmented reality (AR) smart glasses is conducted to demonstrate the above methodology, with the result indicating that the functions of voice commands, 3D visualization, and phone calls should be focused on for the next generation of smart glasses.
\end{abstract}

Keywords: new product development; project portfolio; sustainability; supply chain performance; smart glasses

\section{Introduction}

Product innovation is essential for most of the supply chains in the global market in order to create enhanced value for customers, to enable business survival, and to increase business competitiveness [1]. In general, a 'product' innovated from the new product development (NPD) process includes both tangible (e.g., smartphones and computers) and intangible (e.g., information technology solutions) innovation. Although product innovation and NPD are essential to most business organizations, developing successful new products has always been an underlying challenge in the global market [2]. For example, in 2012, Google Glass was regarded as a well-known product innovation failure, which was caused by an unfashionable product design, an inappropriate pricing strategy, and privacy issues [3]. Subsequently, Google withdrew the product in 2015 due to its unsatisfactory sales performance. Similarly, Amazon launched the Fire Phone in 2014, and customers questioned the value of its core differentiator, namely its 3D face scanning technology [4]. Finally, the Fire Phone was withdrawn in 2015 with a capital loss of approximately USD 170 million. Regarding service innovation failure, Facebook introduced a service, called Facebook Home, which changed the user's home screen into the Facebook news feed [5]. However, it was criticized on the grounds of customization, data consumption, and power efficiency, and Facebook thus disbanded the entire project shortly after the service was released. Since innovation failures may incur huge capital losses and resource wastage, recent research studies tend to focus on building an effective NPD project portfolio rather 
than simply creating new values and innovative elements of new products [6]. In project portfolio management (PPM) for NPD, a number of criteria, such as marketing effectiveness, manufacturing capability, and development costs, are considered and balanced so as to select the most appropriate project portfolio according to the business vision and company capability in a customized manner. In addition to the economic and engineering perspectives of product innovation, sustainability in NPD is becoming increasingly important nowadays in order to enhance the NPDs' project performance in the market [7]. Consequently, several key performance indicators (KPIs) related to sustainable design are considered to make proper project decisions. In recent years, successful product innovation considers not only profitability and technical capability in the project portfolio but also sustainability in order to minimize environmental impact so as to align with the trend of eco-innovation. Therefore, there is a need to incorporate factors related to sustainability in the NPD project portfolio. As shown in Figure 1, the research focus of this study is graphically illustrated in two aspects, namely (i) the systematic approach to derive NPD projects from the current market and (ii) assessment of the NPD projects by considering supply chain performance metrics. This results in determining optimal and sustainable NPD projects in the current market.

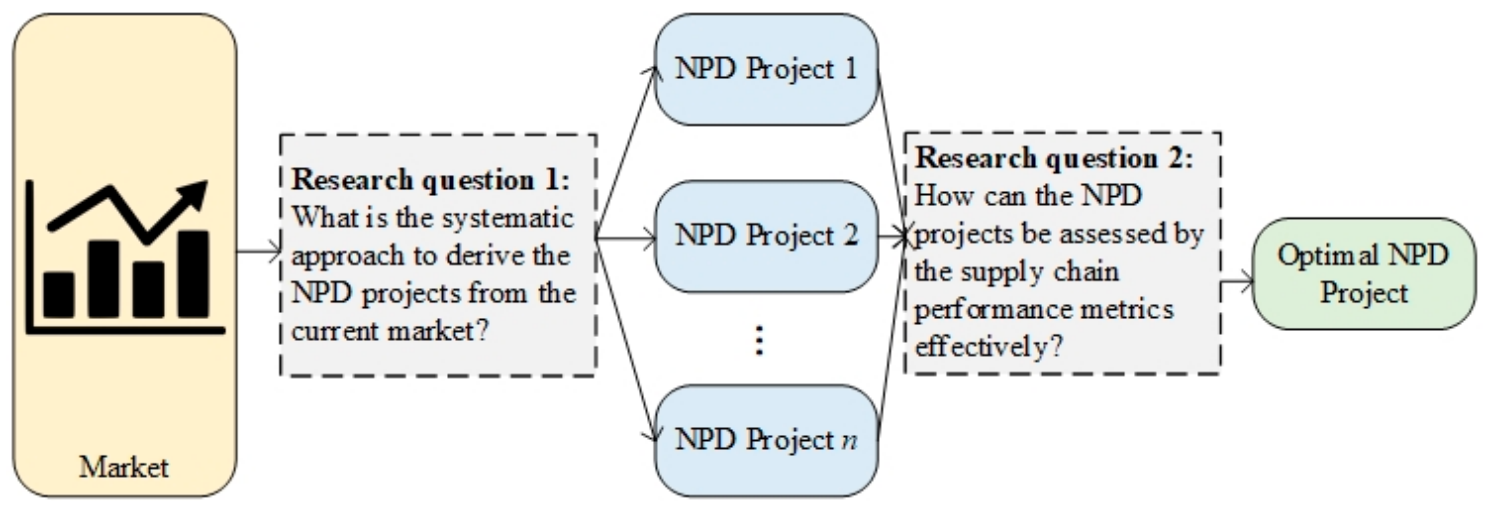

Figure 1. Research focus of this study.

In this study, a two-stage methodology is proposed to structure the NPD project formulation process and project portfolio selection, where the Bayesian best worst method (Bayesian BWM) and fuzzy technique for order of preference by similarity to ideal solution (fuzzy TOPSIS) are adopted to support the multi-criteria decision-making process. The use of the above methods can effectively address the probabilistic and group decision-making process in multi-criteria decision-making (MCDM) problems. Firstly, features for product innovation are collected by analyzing the existing market and are then ranked according to their importance using Bayesian BWM. Subsequently, a number of potential NPD projects can be formulated to address market needs and a company's requirements. Secondly, NPD project portfolio selection is performed using fuzzy TOPSIS, where the criteria in the selection problem are derived from the sustainable supply chain operation reference (SustainableSCOR) model. Thus, the attributes of reliability, responsiveness, agility, cost, asset management efficiency, and sustainability are considered to select the most appropriate project portfolio. In order to examine the feasibility of the above methodology, a case study of the development of augmented reality (AR) smart glasses is conducted. The outstanding features from the existing smart glasses are summarized from the market to assist the NPD project formulation, while the optimal project portfolio for the AR smart glasses is determined. Consequently, this research study enriches the research in product innovation, which embeds the concepts of sustainable design and eco-innovation. Insights of product innovation to determine the better market positioning of smart glasses can be obtained.

This paper is organized as follows: Section 2 reviews NPD and project portfolio management, smart glasses development, and MCDM approaches. Section 3 introduces the proposed two-stage methodology to formulate and select the most appropriate NPD 
project portfolio. A case study of AR smart glasses is presented in Section 4. The results and discussion are provided in Section 5. Finally, conclusions are drawn in Section 6.

\section{Literature Review}

In this section, recent research studies focusing on the following three fields are reviewed: (i) NPD and project portfolio management, (ii) overview of smart glasses, and (iii) MCDM approaches. This allows for identification of research gaps.

\subsection{New Product Development and Project Portfolio Management}

Regarding NPD, design thinking is a practical method of coping with problems in the NPD process. The approach of design thinking was originally implemented by David Kelley and Tim Brown, the executive chairs in the innovation design company of IDEO. It integrates the humanistic intention of design into a synthesized concept [8]. Design thinking is beneficial for designers in applying both product and service innovation during the end-to-end development process rather than the design phase only. Before developing a new product or service, designers should consider the problems to be solved, aiming at targets and development objectives. It is crucial to assist designers in considering the overall user experience of new products and not only the appearance and quality of the design. There are five steps that summarize the stages in the adoption of design thinking: (i) empathizing users' needs, (ii) defining the problems to be tackled, (iii) ideating new product designs with assumptions, (iv) prototyping to create a draft solution, and (v) testing to fine tune the new products/services before launching.

With the mindset of design thinking in developing a new product, two well-known methods help identify customer requirements effectively, namely quality function deployment (QFD) and axiomatic design (AD). On the one hand, QFD is a structured method with a set of tools used to effectively identify customer requirements and to convert them into the corresponding technical achievements with detailed engineering specifications and plans $[9,10]$. The methodology of QFD is divided into four phases, covering the activities in the entire product development cycle. The matrix structure is utilized in each phase to convert the customer's voice into each system so as to formulate the design requirements of the components. Each phase or matrix represents a specific aspect of product requirement. First, the product planning matrix is used to obtain information from customers that is important for the success of the entire QFD process. Second, the assembly/part deployment matrix creates product concepts, and some of the specifications are documented to determine the most critical parts for fulfilling customer requirements. Third, the process planning matrix is deployed for the manufacturing process flows and for recording the process parameters. Fourth, the process/quality control matrix generates performance indicators to monitor the production process, maintenance schedules, and training for operators. On the other hand, $\mathrm{AD}$ is another approach for systematically making good design with a scientific basis [11,12]. There are two axioms for new product development to be utilized. Axiom one features the need for maintaining the independence of the functional requirements, while axiom two features minimizing the information content to fulfil the functional requirements. Subsequently, a good design of functional requirements is suggested to be independent and uncoupled. Regarding the entire design process by means of $\mathrm{AD}$, there are four major domains, namely the customer domain, the functional domain, the physical domain, and the process domain. In the customer domain, the customer needs and expectations are determined in order to turn them into design specifications. In the functional domain, the appropriate set of functional requirements is identified to fulfil the customers' needs. In the physical domain, the actual design components are sourced to stratify the technical requirements on the functional requirements. In the process domain, the manufacturing process for the NPD is optimized to achieve the planned functional requirements of the product. Currently, increasingly more research is unlocking the power of state-of-the-art technologies and paradigms in the area of NPD to enhance not only productivity and production efficiency but also sus- 
tainability and customer-centric design [13-15]. To manage NPD projects effectively, the concept of project portfolio management has recently drawn considerable attention for evaluating NPD projects by considering a set of critical success factors [16]. Ten criteria, namely project mission, top management support, project schedule, client consultation, personnel, technical tasks, client acceptance, monitoring and feedback, communication, and troubleshooting, are considered in building the project implementation profile. Apart from the above internal factors, the evaluation of NPD projects should be further extended to the supply chain perspective so as to enhance sustainability and competitiveness in the market.

\subsection{Multi-Criteria Decision-Making Approaches}

To make appropriate decisions by considering multiple criteria, the research on multicriteria decision-making (MCDM) approaches is promising, for example, the analytic hierarchy process (AHP) [17], the best worst method (BWM) [18], and the technique for order of preference by similarity to ideal solution (TOPSIS) [19]. In this study, our aim is to (i) compare and rank the features of AR smart glasses on the market and (ii) select the most appropriate development project portfolio. To compare various product features, BWM is a promising tool and outperforms the AHP in terms of comparison complexity and result consistency [18]. Furthermore, BWM has now been extended to analyze group decision-making and probabilistic behavior in pairwise comparisons [20], which is effective in conducting pairwise comparisons for a group of decision makers. On the other hand, the assessment of NPD projects with various dimensions, which may contradict each other, can be carried out using TOPSIS. Instead of conducting the comparison between NPD projects, the use of TOPSIS focuses on the trade-off among various criteria in order to obtain an 'ideal solution'. To facilitate the decision-making process, fuzzy TOPSIS was developed to counter fuzziness and vagueness when building a decision matrix, where it is convenient for decision makers to assign the proper weightings on each criterion [21]. Therefore, the Bayesian BWM and fuzzy TOPSIS are selected in this study to address the research focus mentioned above, namely product feature ranking to formulate project portfolios and project portfolio selection based on the SustainableSCOR model.

\subsection{Summary of the Literature Review}

Among numerous emerging technological products, the development of smart glasses is important, but it is challenging to formulate a feasible and effective product design. For virtual reality (VR) products, the market for enterprise solutions has been developed to a sophisticated level, but the consumer market is far smaller than the enterprise market. When developing AR smart glasses, they are targeted as an associate product to the smartphone, or even a replacement of the smartphone in the future. Therefore, an effective NPD process is guided by existing product development methods where analyzing essential product features of smart glasses is required so that new products with a higher likelihood of NPD success can be expected. Therefore, the product design team should focus on selected product features for further enhancement and optimization.

\section{Methodology}

In this section, a two-stage methodology for product innovation and project portfolio selection is proposed as depicted in Figure 2. In general, the proposed methodology is to assist the product innovation process in the formulation of various NPD projects and to select the most appropriate project from the perspective of sustainable supply chain performance measurement. In the proposed methodology, the Bayesian BWM and fuzzy TOPSIS are selected as the major methods for data analysis. For the Bayesian BWM, pairwise comparisons for multiple product features are conducted and analyzed in a group decision-making process such that the perspectives from multiple stakeholders are synthesized to prioritize product features in a systematic manner. Its effectiveness in prioritizing factors has been proven, and it outperformed another existing multi-criteria 
decision-making (MCDM) approach, namely AHP [18]. On the other hand, the fuzzy TOPSIS is promising for assisting the selection decision when contradictive criteria are considered so as to derive the ideal solution. Moreover, the SustainableSCOR model can be effectively converted to the criteria to be considered in the fuzzy TOPSIS. Due to the incorporation of fuzzy set theories, the perspectives of decision makers can be presented by linguistic variables to enhance the ease of data collection. Overall speaking, the Bayesian BWM and fuzzy TOPSIS are suitable approaches to prioritize product features and select the most appropriate NPD project so that the selected NPD project is relatively sustainable and competitive from the supply chain perspective.

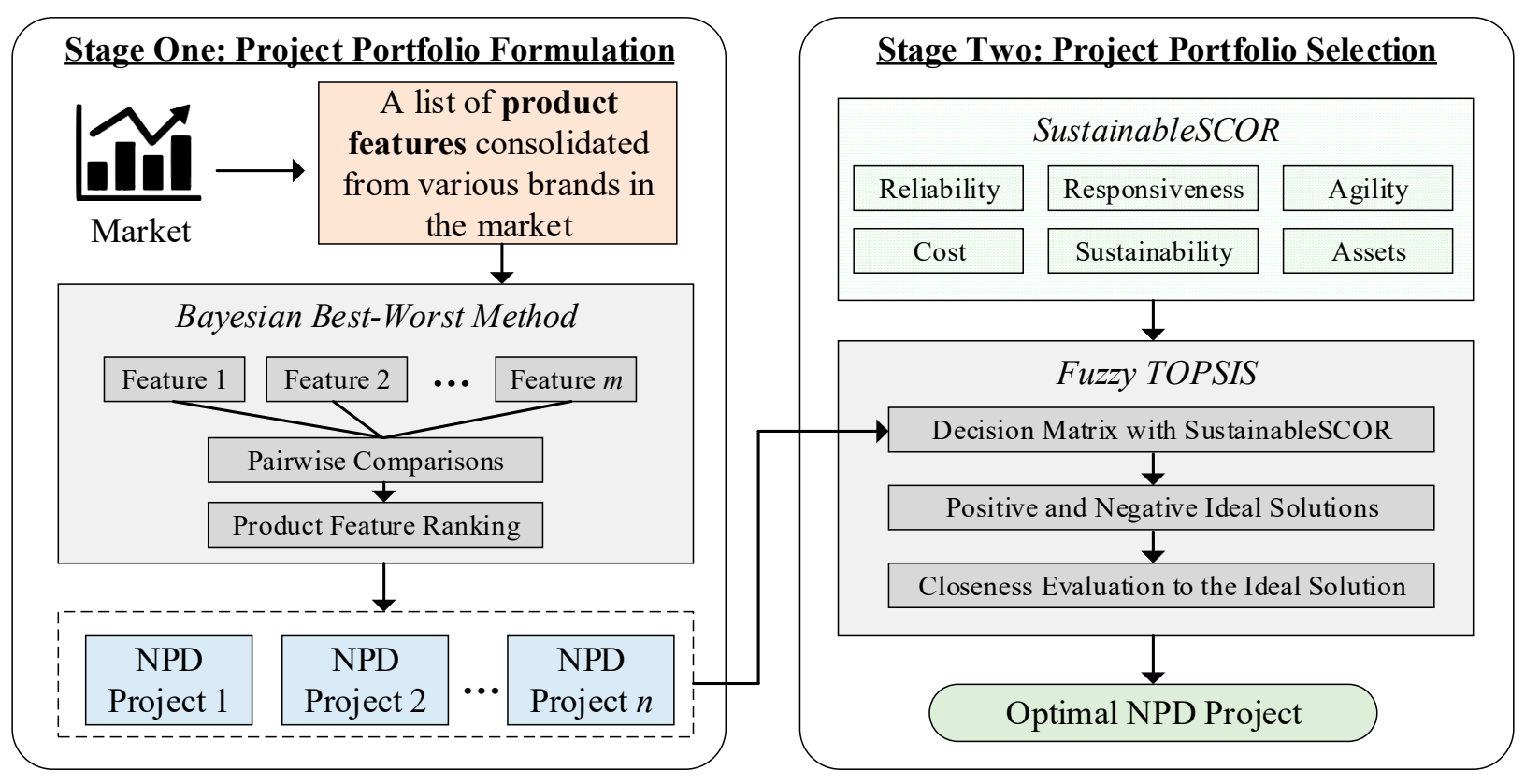

Figure 2. Framework of the proposed two-stage methodology.

\subsection{Stage One: Project Portfolio Formulation}

Generally, product innovation can generate completely new products, additions to existing product lines, or modifications of existing products, and, therefore, a comprehensive investigation of the current market is of the utmost importance. By studying a number of existing products and brands on the market, a list of emerging product features $\mathrm{F}=\left\{f_{1}, f_{2}, \ldots, f_{m}\right\}$ can be summarized, which can be the key differentiators on the market. Since product features are diversified in the market, particularly in regard to AR smart glasses, a combination of different sets of product features can be constructed. In order to study the priority of product features in the formulation of NPD projects, the Bayesian BWM is adopted, where a group of decision makers are invited to conduct pairwise comparisons so as to construct the best-to-others and others-to-worst vectors as demonstrated in Equations (1) and (2). Each decision maker $k$ is thus required to conduct $2 m-3$ comparisons in total, where $m$ is the number of considered product features.

$$
\begin{gathered}
V_{B}^{k}=\left(v_{B 1}, v_{B 2}, \ldots, v_{B m}\right) \\
V_{W}^{k}=\left(v_{1 W}, v_{2 W}, \ldots, v_{m W}\right)^{T}
\end{gathered}
$$

In order to aggregate the weights from various decision makers, the group decisionmaking process is modeled using a Bayesian model such that a joint probability distribution is built to estimate the aggregated weight $w^{*}$ and the optimal criterion weights of $k$ decision makers $w^{1: k}$ based on the collected best-to-others $V_{B}^{1: k}$ and others-to-worst $V_{W}^{1: k}$ vectors. The above joint probability distribution is mathematically expressed as the conditional probability in Equation (3). In this model, the collected vectors related to the pairwise 
comparisons are the observed variables, namely the inputs, which are dependent and used to estimate the optimal weights of $k$ decision makers. In addition, the aggregated weight $w^{*}$ is dependent on the optimal weights $w^{1: k}$. By applying the Bayes theorem, the joint probability distribution in Equation (3) can be simplified into a hierarchical structure as demonstrated in Equation (4).

$$
\begin{gathered}
P\left(w^{*}, w^{1: k} \mid V_{B}^{1: k}, V_{W}^{1: k}\right) \\
P\left(w^{*}\right) \prod_{i=1}^{k}\left[P\left(V_{W}^{i} \mid w^{i}\right) \cdot P\left(V_{B}^{i} \mid w^{i}\right) \cdot P\left(w^{i} \mid w^{*}\right)\right]
\end{gathered}
$$

With regard to the distributions of elements in Equation (4), the elements $V_{W}^{i}$ and $V_{B}^{i}$ are modeled by the multinomial distribution such that $V_{W}^{i} \mid w^{i} \sim \operatorname{multinomial}\left(w^{i}\right)$ and $V_{B}^{i} \mid w^{i} \sim \operatorname{multinomial}\left(\frac{1}{w}^{i}\right)$, where $\forall i \in 1, \ldots, k$. In addition, the Dirichlet distribution is reparametrized to model $w^{i}$ with respect to the mean of the distribution $w^{*}$ and a concentration parameter $\gamma$, such that $w^{i} \mid w^{*} \sim \operatorname{Dir}\left(\gamma \cdot w^{*}\right)$, where the parameter $\gamma$ is modeled in a gamma distribution. Consequently, for computing the posterior distribution, a Markov chain Monte Carlo technique, namely Just Another Gibbs Sampler (JAGS), is applied, and, thus, the posterior distribution of weights for decision makers and the aggregated weight can be obtained. In addition, credal ranking as a ranking scheme for the decision criteria can be constructed to investigate the confidence levels between various criteria. It shows the interrelations of the criteria so as to determine the superiority of product features in the product innovation process. Based on the aggregated weight and credal ranking, several feasible NPD projects can be formulated based on the preferences of the market, while the most appropriate project is then selected in stage two based on their sustainability and supply chain performance.

\subsection{Stage Two: Project Portfolio Selection}

After the formulation of various NPD projects, the projects are still at the planning stage and are difficult to measure using quantitative performance metrics. In this stage, fuzzy TOPSIS is adopted to facilitate the selection decision based on the SustainableSCOR model derived from the SCOR model [22]. In the SustainableSCOR model, there are six major performance attributes, namely reliability, responsiveness, agility, cost, assets, and sustainability, as shown in Table 1, where some sample metrics are provided to evaluate the levels of performance attributes. Subsequently, the NPD projects can be measured in a multi-dimensional manner to derive the most appropriate NPD project for further investigation.

Mathematically speaking, the decision matrix D is expressed in Equation (5), where rmn denotes the rating between the number of NPD projects $P=\{1,2, \ldots, p\}$ and the evaluation dimension $E=\{1,2, \ldots, e\}$.

$$
\mathbf{D}=\left[\begin{array}{ccc}
r_{11} & \cdots & r_{1 \mathrm{e}} \\
\vdots & \ddots & \vdots \\
r_{\mathrm{p} 1} & \cdots & r_{p e}
\end{array}\right], \forall p \in P \text { and } \forall e \in E
$$

After the decision matrix with the six evaluation dimensions is built, fuzzy TOPSIS is then adopted to evaluate the NPD projects according to the six defined dimensions. The detailed steps of deploying fuzzy TOPSIS are as follows: In Step 1, a group of $q$ decision makers in the companies, who possess professional knowledge and expertise in the targeted research domain, is identified, and they are required to evaluate the NPD projects based on the six dimensions of the supply chain performance. In Step 2, the group of $q$ decision makers need to conduct evaluations for all NPD projects for each dimension. The evaluations are rated using linguistic terms, as shown in Table 2, to assess the supply 
chain performance according to the SustainableSCOR model. Table 2 shows the conversion from linguistic terms to triangular fuzzy numbers based on the Saaty scale.

Table 1. Six major dimensions in the SustainableSCOR model.

\begin{tabular}{llll}
\hline Dimension & Description & Metrics to Be Considered \\
\hline Reliability & $\begin{array}{l}\text { The degree of yielding consistent supply chain } \\
\text { performance to satisfy the market demand. }\end{array}$ & Perfect order fulfilment \\
\hline Responsiveness & $\begin{array}{l}\text { The degree of responding purposefully to requests and } \\
\text { changes in the market. }\end{array}$ & - & Order fulfilment cycle time \\
\hline \multirow{2}{*}{ Agility } & $\begin{array}{l}\text { The degree of adjusting supply chain tactics and } \\
\text { operations to address demand volatility. }\end{array}$ & - & $\begin{array}{l}\text { Upside and downside supply chain } \\
\text { adaptability } \\
\text { Overall value at risk }\end{array}$ \\
\hline \multirow{2}{*}{ Cost } & $\begin{array}{l}\text { The degree of capital resources used in investment, } \\
\text { transportation, procurement, production, and inventory. }\end{array}$ & - & $\begin{array}{l}\text { Total supply chain management cost } \\
\text { Costs of goods sold }\end{array}$ \\
\hline \multirow{3}{*}{ Assets } & The degree of asset utilization in supply chain activities \\
and asset liquidity for companies. & - & $\begin{array}{l}\text { Cash-to-cash cycle time } \\
\text { Return on supply chain fixed assets } \\
\text { Return on working capital }\end{array}$ \\
\hline \multirow{2}{*}{ Sustainability } & The degree of environmental, social, and economic & - & $\begin{array}{l}\text { Waste generation } \\
\text { impacts throughout the whole product lifecycle. } \\
\text { Carbon consumption }\end{array}$ \\
\hline
\end{tabular}

Table 2. Conversion between linguistic terms and triangular fuzzy numbers.

\begin{tabular}{cc}
\hline Linguistic Terms (Label) & Triangular Fuzzy Number \\
\hline Very Low (VL) & $(1,1,3)$ \\
\hline Low (L) & $(1,3,5)$ \\
\hline Average (A) & $(3,5,7)$ \\
\hline High (H) & $(5,7,9)$ \\
\hline Very High (H) & $(7,9,9)$ \\
\hline
\end{tabular}

In Step 3, all the pairwise comparisons from different decision makers are combined to establish a combined decision matrix, where the combined rating $\hat{r}_{p e}=\left(\hat{l}_{p e}, \hat{a}_{p e}, \hat{u}_{p e}\right)$ represents the lower bound, mid-point, and upper bound of a triangular fuzzy number. The value $\hat{l}_{p e}$ is evaluated by $\min _{q}\left(l_{p e}^{q}\right)$; the value $\hat{a}_{p e}$ is evaluated by the average of $a_{p e}^{q}$; the value $\hat{u}_{p e}$ is evaluated by $\max _{q}\left(u_{p e}^{q}\right)$. In Step 4 , the benefits and cost characteristics of the evaluation dimensions are determined, which refer to being favorable to and against the goal of selecting the most valuable product features, respectively. Subsequently, the combined decision matrix can be normalized, i.e., $\left[n_{p e}\right]=\left(\widetilde{l}_{p e}, \widetilde{a}_{p e}, \widetilde{u}_{p e}\right)$, at each evaluation dimension as demonstrated in Equation (6). In the SustainableSCOR model, the dimensions of reliability, agility, responsiveness, assets, and sustainability are the beneficial characteristics, while the dimension of cost is the cost characteristic. In addition, the fuzzy preferences on evaluation dimensions are multiplied with the normalized decision matrix to the weighted normalized decision matrix as demonstrated in Equation (7).

$$
\begin{gathered}
n_{p e}=\left\{\begin{array}{c}
\left(\frac{l_{p e}}{u_{p e}^{+}}, \frac{a_{p e}}{u_{p e}^{+}}, \frac{u_{p e}}{u_{p e}^{+}}\right), \text {where } u_{e}^{+}=\max _{e}\left(u_{p e}\right) \\
\left(\frac{l_{p e}^{-}}{u_{p e}}, \frac{l_{p e}^{-}}{a_{p e}}, \frac{l_{p e}^{-}}{l_{p e}}\right), \text { where } l_{e}^{-}=\min _{e}\left(l_{p e}\right)
\end{array}\right. \\
v_{p e}=n_{p e} \cdot \omega_{e}^{*}=\left(\widetilde{l}_{p e}, \widetilde{a}_{p e}, \widetilde{u}_{p e}\right) \otimes\left(l_{e}^{*}, a_{e}^{*}, u_{e}^{*}\right)
\end{gathered}
$$


In Step 5, by making use of the weighted normalized decision matrix, the fuzzy positive ideal solution (i.e., $\mathrm{E}^{+}$) and the fuzzy negative ideal solution (i.e., $\mathrm{E}^{-}$) are computed as demonstrated in Equation (8). The largest vector in every evaluation dimension is collected to build set $\mathrm{E}^{+}$, while the smallest vector in every evaluation dimension is collected to construct set $\mathrm{E}^{-}$.

$$
\mathrm{E}^{ \pm}=\left(v_{1}^{ \pm}, v_{2}^{ \pm}, \ldots, v_{j}^{ \pm}, \ldots, v_{e}^{ \pm}\right), \text {where } v_{j}^{+}=\max _{p}\left(v_{p j}\right) \text { and } v_{j}^{-}=\min _{p}\left(v_{p j}\right)
$$

In Step 6, distances from the weighted normalized ratings to $\mathrm{E}^{+}$and $\mathrm{E}^{-}$are calculated to form the distance values $d_{m n}^{+}$and $d_{m n}^{-}$, respectively, as demonstrated in Equation (9). Therefore, the closeness coefficient for all product features can be evaluated as demonstrated in Equation (10), where $\Delta_{p}^{ \pm}=\sum_{j=1}^{e}\left(d_{p j}^{ \pm}\right), \forall p \in P$. Consequently, the NPD projects can be ranked accordingly from the highest to the lowest closeness coefficient, and the NPD project with the highest closeness coefficient is selected for further development.

$$
\begin{gathered}
d_{p e}^{ \pm}=\left|v_{p e}-v_{e}^{ \pm}\right|=\sqrt{\frac{1}{3}\left[\left(l_{p e}-l_{e}^{ \pm}\right)^{2}+\left(a_{p e}-a_{e}^{ \pm}\right)^{2}+\left(u_{p e}-u_{e}^{ \pm}\right)^{2}\right]} \\
C C_{p}=\frac{\Delta_{p}^{-}}{\Delta_{p}^{-}+\Delta_{p}^{+}}
\end{gathered}
$$

\section{Case Study}

In this section, the proposed methodology is implemented to assist the product innovation process of AR smart glasses in the context of project portfolio formulation and project portfolio selection. The aim is to formulate an NPD project portfolio for the development of AR smart glasses, satisfying market preferences and improving supply chain performance.

\subsection{Overview of the Smart Glasses Market}

Since immersive technologies entered the consumer market in 2014, products enabling immersive technologies, such as virtual reality (VR), have become the core themes of major information communication technology (ICT) advancements in recent years. Smart glasses are wearable computing devices and are worn in front of the eyes similar to ordinary glasses except that digital content overlays vision [23]. To adjust and enrich the wearers' perception, there are three immersive technologies that are adopted, namely VR, AR, and mixed reality (MR) [24]. VR creates an entirely virtual world while allowing users to simulate a highly realistic environment. The completely artificial 3D world provides a kind of illusion with the effect of visual, auditory, interactive, and other sensory-stimulating elements. The better developed the aforementioned items are, the more realistic the virtual environment obtained is as an immersive environment. The major characteristic of VR is that only the virtual world reflects the user's actions without the effect of light sources or real-world interactions. AR is an enhanced technology that originated from VR. VR keeps users completely separated from the physical world in order to take part in the virtual environment, whereas AR augments virtual objects to the real environment [25]. Users perceive digital content generated by a computing device, which acts as a communication medium that allows interaction with the digital content. MR is the combination of VR and $\mathrm{AR}$ as a whole, where a new environment is created with the coexistence of physical and digital objects in real time. The user can interact with them by wearing holographic devices. Not only can the user perceive virtual content, but physical objects located in the user's actual surroundings can also interact with the virtual objects. As a result, MR is more complicated than VR and AR and requires more computing power and resources to realize virtual objects in the physical world. Smart glasses are widely adopted in multiple areas, such as engineering [26], healthcare [27], and education [28]. However, the development 
of AR applications is not yet at a mature stage due to few standardized designs and user development processes on the market. Consequently, there is still room for improvement and development of successful smart glasses and applications.

\subsection{Implementation and Data Collection of the Proposed Methodology for AR Smart Glassess}

Due to the emergence of AR smart glasses on the market, there is a huge market potential for conducting research and development activities to build novel and innovative smart glasses for consumers. Therefore, the market preferences for AR smart glasses are studied to build several NPD projects, while the most appropriate one is selected according to the evaluation of sustainability and supply chain performance.

To deploy the proposed two-stage methodology, data on aspects of market preferences and an evaluation using the SustainableSCOR model are required. Firstly, a focus group was conducted in the case company involving nine interviewees who were invited to participate in a survey for pairwise comparisons between ten outstanding product features of smart glasses available on the market on 8th May 2021. The profiles of the nine interviewees are presented in Table 3. Seven male and two female staff members who worked for the case company for about 2.6 years on average were interviewed, seven of them were aged between 36 and 45 and only two between 26 and 35. The interviewees were required to select the best and worst product features and compare the best and worst features with other features using a scale 1 to 9 (where 1 refers to equal importance, and 9 refers to absolute importance). Subsequently, a total of eighteen best-to-others and other-to-worst vectors were formulated. Secondly, when several NPD project portfolios were suggested, two domain experts (managerial grade or above) working in the electronics manufacturing company were invited to evaluate the NPD projects based on the six performance attributes in the SustainableSCOR model using the linguistic terms depicted in Table 2.

Table 3. Profile of the focus group interviewees from the case company.

\begin{tabular}{ccccc}
\hline$\#$ & Gender & Age & Post Title & $\begin{array}{c}\text { Work Duration in the Case } \\
\text { Company (Years) }\end{array}$ \\
\hline D1 & Male & $36-45$ & Operation Director & 6 \\
\hline D2 & Male & $36-45$ & Product Development Engineer & 2 \\
\hline D3 & Female & $36-45$ & Project Manager & 0.2 \\
\hline D4 & Male & $36-45$ & Electric Engineering Manager & 3 \\
\hline D5 & Male & $36-45$ & Software Engineer & 4 \\
\hline D6 & Male & $36-45$ & Product Development Engineer & 4 \\
\hline D7 & Female & $26-35$ & Project Manager & 0.5 \\
\hline D8 & Male & $36-45$ & Supply Chain Specialist & 1.5 \\
\hline D9 & Male & $26-35$ & Product Structural Engineer & 2 \\
\hline
\end{tabular}

\section{Results}

In this section, the results of the aforementioned implementation in the case company are presented, including (i) feature ranking and project formulation of AR smart glasses and (ii) NPD project portfolio selection of AR smart glasses. Ultimately, the most appropriate NPD project for developing AR smart glasses in the case company can be finalized.

\subsection{Feature Ranking and Project Formulation of AR Smart Glasses}

Regarding the existing smart glasses on the market, Table 4 summarizes the features of six existing brands, namely Epson ${ }^{\circledR}$ Moverio BT-300 (Brand A), Nreal ${ }^{\circledR}$ Light (Brand B), Rokid $^{\circledR}$ (Brand C), Focals by North ${ }^{\circledR}$ (Brand D), Vuzix Blade ${ }^{\circledR}$ (Brand E), and MAD Gaze ${ }^{\circledR}$ GLOW (Brand F). To summarize, there are ten common features among these models of smart glasses, and they are as follows: 
- Navigation (F1): This provides routing directions in real time by obtaining position data. Smart glasses allow digital objects, such as traffic signals, to be augmented on the glasses.

- $\quad$ Phone Calling (F2): This allows users to contact someone via a telephone network.

- Social Media and Messaging (F3): This refers to social media websites and applications, such as Facebook, Instagram, and MeWe. These allow users to widely share their opinions and engage with the public. Messaging services, such as Whatsapp, Wechat, and Line, allow users to send texts or other formats of content with friends/relatives anywhere and anytime.

- $\quad$ Live Streaming (F4): This refers to online streaming applications that record and broadcast simultaneously in real time, such as Twitch and Instagram, such that an audience can be reached online.

- Real-time Translation (F5): Multilingual technology allows users to record audio or typed texts for translation into other languages to establish an efficient way of communicating with foreign-language speakers.

- Prescription Lenses (F6): These are developed for users who have varying degrees of short-sightedness, long-sightedness, and astigmatism. Customization services for users with prescription lenses are provided for smart glasses by optical professionals.

- Gesture Control (F7): Hand-tracking sensors are embedded to capture the user's hand gestures and control the devices.

- Voice Commands (F8): This allows users to control the smart glasses using voice only, which is a hands-free mode. With the help of built-in virtual assistants, such as Alexa and Siri, voice commands can be given to order smart glasses to perform specific tasks.

- Image, video, and audio recordings (F9): Each smart glass component has an embedded camera, which allows users to capture images and videos, as well as to record audio for entertainment.

- 3D Visualization (F10): Smart glasses are equipped to visualize three-dimensional (3D) objects such that users can watch and modify 3D objects smoothly in the smart glasses' environment.

Table 4. Product features of smart glasses on the market.

\begin{tabular}{lllllll}
\hline & \multicolumn{7}{c}{ Brand } \\
\hline Features & A & B & C & D & E & F \\
\hline Navigation (F1) & O & O & O & $\sqrt{ }$ & $\sqrt{ }$ & O \\
\hline Phone Calling (F2) & O & O & O & $\sqrt{ }$ & O \\
\hline Social Media and Messaging (F3) & O & O & O & $\sqrt{ }$ & $\sqrt{ }$ & $\mathrm{O}$ \\
\hline Live Streaming (F4) & O & O & & & & $\mathrm{O}$ \\
\hline Real-time Translation (F5) & $\mathrm{O}$ & & & & $\sqrt{ }$ & $\mathrm{O}$ \\
\hline Prescription Lenses (F6) & $\sqrt{ }$ & $\sqrt{ }$ & $\sqrt{ }$ & $\sqrt{ }$ & $\sqrt{ }$ & $\sqrt{ }$ \\
\hline Gesture Control (F7) & & $\mathrm{O}$ & & & & $\mathrm{O}$ \\
\hline Voice Commands (F8) & $\mathrm{O}$ & $\mathrm{O}$ & $\mathrm{O}$ & $\sqrt{ }$ & $\sqrt{ }$ & $\mathrm{O}$ \\
\hline Image, video and audio recordings (F9) & $\mathrm{O}$ & $\sqrt{ }$ & $\sqrt{ }$ & & $\sqrt{ }$ & $\mathrm{O}$ \\
\hline 3D Visualization (F10) & & $\mathrm{O}$ & $\mathrm{O}$ & & $\mathrm{O}$ \\
\hline
\end{tabular}

Remark: " $\sqrt{ }$ " refers to features that are performed independently and standalone; "O" $\mathrm{O}$ "refers to features that are performed via a wired connection with smartphones and computers.

Based on the data collected from the focus group interviews, the best-to-others and others-to-worst vectors are formulated, as shown in Table 5, to be analyzed by means of Bayesian BWM. The importance of the smart glasses' features is prioritized by the interviewees as listed in Table 3, who were actively involved in new product development of the smart glasses in the case company. 
Table 5. Best-to-others and others-to-worst vectors for the Bayesian BWM.

\begin{tabular}{|c|c|c|c|c|c|c|c|c|c|c|}
\hline & & \multicolumn{9}{|c|}{ Features } \\
\hline & & F1 & F2 & F3 & F4 & F5 & F6 & F7 & F8 & F9 \\
\hline \multirow{9}{*}{ Best-to-Others } & D1 & 3 & 1 & 5 & 5 & 3 & 5 & 5 & 5 & 5 \\
\hline & D2 & 1 & 1 & 3 & 3 & 2 & 1 & 2 & 1 & 1 \\
\hline & D3 & 7 & 7 & 6 & 5 & 5 & 9 & 5 & 8 & 6 \\
\hline & D4 & 6 & 1 & 3 & 1 & 3 & 1 & 3 & 6 & 1 \\
\hline & D5 & 3 & 4 & 2 & 5 & 1 & 9 & 6 & 1 & 7 \\
\hline & D6 & 1 & 1 & 1 & 1 & 1 & 1 & 1 & 1 & 1 \\
\hline & D7 & 1 & 3 & 3 & 3 & 3 & 3 & 3 & 3 & 3 \\
\hline & D8 & 7 & 4 & 1 & 6 & 7 & 1 & 3 & 7 & 7 \\
\hline & D9 & 4 & 1 & 2 & 6 & 6 & 1 & 6 & 4 & 2 \\
\hline \multirow{9}{*}{ Others-to-Worst } & D1 & 9 & 9 & 7 & 5 & 7 & 7 & 1 & 7 & 7 \\
\hline & D2 & 1 & 1 & 2 & 1 & 2 & 9 & 3 & 9 & 2 \\
\hline & D3 & 5 & 5 & 5 & 5 & 5 & 1 & 5 & 5 & 5 \\
\hline & D4 & 1 & 9 & 7 & 9 & 7 & 9 & 9 & 9 & 9 \\
\hline & D5 & 2 & 5 & 7 & 6 & 8 & 1 & 3 & 9 & 2 \\
\hline & D6 & 1 & 3 & 3 & 3 & 2 & 3 & 5 & 5 & 9 \\
\hline & D7 & 4 & 1 & 3 & 4 & 4 & 4 & 4 & 4 & 4 \\
\hline & D8 & 7 & 7 & 4 & 4 & 7 & 7 & 1 & 7 & 7 \\
\hline & D9 & 9 & 9 & 9 & 1 & 9 & 9 & 9 & 9 & 9 \\
\hline
\end{tabular}

Based on the results of applying the Bayesian BWM, the credal ranking between the smart glasses' features was built as shown in Figure 3. It was found that voice command, $3 \mathrm{D}$ visualization, and phone call features were the top three elements for the development of new smart glasses, and the entire credal ranking can be used to assist the NPD project formulation process. The live streaming feature is regarded as the lowest influential feature for designing and developing smart glasses. Subsequently, the credal ranking of smart glasses' features can be supportive at the front end of the innovation so as to understand the design criteria and specification. When designing the next generation of smart glasses, the preferable features, namely voice commands, 3D visualization, and phone calls, should be concentrated on, and, therefore, a clear focus can be established by the research and development team. In particular, a breakthrough in the preferable features is more important than the other features. Based on the above information, five NPD projects can be effectively brainstormed and formulated, which match the preferences and credal ranking of the smart glasses' features. Although the five projects are feasible to the product engineering team, there is no guarantee of a high degree of supply chain performance and sustainability. In the next stage, one of the five projects is selected according to the considerations of the SustainableSCOR model.

\subsection{NPD Project Portfolio Selection of AR Smart Glasses}

Based on the above results of the Bayesian BWM, five NPD project portfolios for smart glasses were formulated, and the product specifications are summarized in Appendix A. To select the most appropriate NPD project for the case company, decision makers are required to rate the importance of the six essential dimensions in the SustainableSCOR model, namely reliability (C1), responsiveness (C2), agility (C3), cost (C4), assets (C5), and sustainability (C6), as shown in Table 6. The linguistic terms are converted into fuzzy numbers according to the conversion table in Table 2. Afterward, the nine decision makers evaluated the five NPD project portfolios one by one according to the six dimensions of 
the SustainableSCOR model. By averaging their inputs, the combined decision matrix between the five NPD project portfolios and dimensions in the SustainableSCOR model was formulated as shown in Table 7.

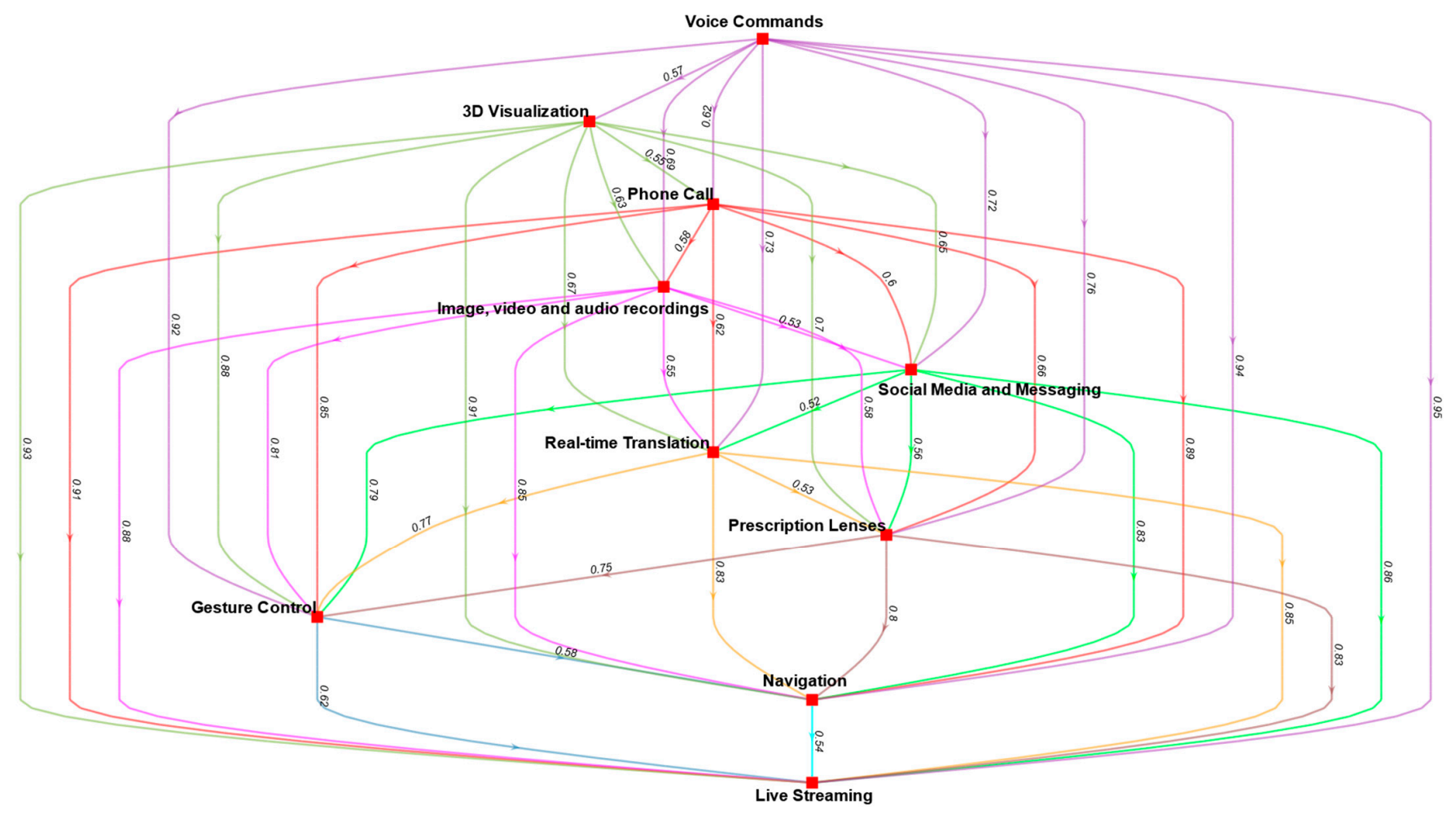

Figure 3. Credal ranking of smart glasses' features.

Table 6. Weightage on the dimensions in the SustainableSCOR model.

\begin{tabular}{ccccccc}
\hline \multicolumn{7}{c}{ Dimensions in the SustainableSCOR Model } \\
\hline C1 & C2 & C3 & C4 & C5 & C6 \\
\hline D1 & $(7,9,9)$ & $(5,7,9)$ & $(5,7,9)$ & $(7,9,9)$ & $(3,5,7)$ & $(5,7,9)$ \\
\hline D2 & $(5,7,9)$ & $(5,7,9)$ & $(5,7,9)$ & $(3,5,7)$ & $(5,7,9)$ & $(5,7,9)$ \\
\hline D3 & $(7,9,9)$ & $(7,9,9)$ & $(5,7,9)$ & $(7,9,9)$ & $(5,7,9)$ & $(7,9,9)$ \\
\hline D4 & $(5,7,9)$ & $(5,7,9)$ & $(3,5,7)$ & $(3,5,7)$ & $(3,5,7)$ & $(3,5,7)$ \\
\hline D5 & $(5,7,9)$ & $(7,9,9)$ & $(7,9,9)$ & $(5,7,9)$ & $(5,7,9)$ & $(5,7,9)$ \\
\hline D6 & $(5,7,9)$ & $(5,7,9)$ & $(5,7,9)$ & $(3,5,7)$ & $(3,5,7)$ & $(5,7,9)$ \\
\hline D7 & $(5,7,9)$ & $(3,5,7)$ & $(3,5,7)$ & $(5,7,9)$ & $(7,9,9)$ & $(7,9,9)$ \\
\hline D8 & $(5,7,9)$ & $(5,7,9)$ & $(5,7,9)$ & $(5,7,9)$ & $(5,7,9)$ & $(5,7,9)$ \\
\hline D9 & $(5,7,9)$ & $(5,7,9)$ & $(5,7,9)$ & $(3,5,7)$ & $(3,5,7)$ & $(5,7,9)$ \\
\hline Average & $(5,7.4,9)$ & $(3,7.2,9)$ & $(3,6.8,9)$ & $(3,6.6,9)$ & $(3,6.3,9)$ & $(3,7.2,9)$ \\
\hline
\end{tabular}

By following the methodology stated in Section 3.2, the normalized fuzzy decision matrix can be built, while the average weightage of the dimensions in the SustainableSCOR was incorporated so as to construct the weighted normalized fuzzy decision matrix. Among the six dimensions of the SustainableSCOR model, the cost (C4) is regarded as the cost criterion, whereas the other dimensions are defined as benefit criteria. Subsequently, the fuzzy positive ideal solution (FPIS) and fuzzy negative ideal solution (FNIS) can be derived, and the distances from each alternative to the FPIS and FNIS can be calculated, respectively. Consequently, the closeness coefficient for the alternatives can be computed such that 
the rank of the NPD project portfolios can be made in descending order of the closeness coefficient as shown in Table 8. It was found that NPD 2 was ranked at the first priority in the case company with a closeness coefficient of 0.7315 . In other words, this implies that the case company is sufficiently confident in having sufficient supply chain capabilities on managing the entire NPD process for NPD 2.

Table 7. Combined decision matrix for the project portfolio selection.

\begin{tabular}{ccccccc}
\hline \multicolumn{7}{c}{ Dimensions in the SustainableSCOR Model } \\
\hline C1 & C2 & C3 & C4 & C5 & C6 \\
\hline NPD 1 & $(3,6.78,9)$ & $(3,6.78,9)$ & $(3,6.56,9)$ & $(3,6.56,9)$ & $(3,6.56,9)$ & $(3,6.78,9)$ \\
\hline NPD 2 & $(3,7.22,9)$ & $(3,7.22,9)$ & $(3,7,9)$ & $(3,6.78,9)$ & $(3,7,9)$ & $(3,7.44,9)$ \\
\hline NPD 3 & $(3,7.22,9)$ & $(3,6.78,9)$ & $(3,7,9)$ & $(3,6.78,9)$ & $(3,6.56,9)$ & $(3,7.22,9)$ \\
\hline NPD 4 & $(3,7,9)$ & $(3,7,9)$ & $(3,7,9)$ & $(3,6.33,9)$ & $(3,6.78,9)$ & $(3,7.22,9)$ \\
\hline NPD 5 & $(1,5.89,9)$ & $(1,6.11,9)$ & $(1,6.33,9)$ & $(1,6.33,9)$ & $(1,6.11,9)$ & $(1,6.56,9)$ \\
\hline
\end{tabular}

Table 8. Closeness coefficient and rank of the NPD project portfolios.

\begin{tabular}{ccccc}
\hline & $\boldsymbol{d}_{\boldsymbol{p e}}^{+}$ & $\boldsymbol{d}_{\boldsymbol{p} e}^{-}$ & $C C_{\boldsymbol{p}}$ & Rank \\
\hline NPD 1 & 2.36 & 2.49 & 0.5134 & 4 \\
\hline NPD 2 & 1.16 & 3.16 & 0.7315 & 1 \\
\hline NPD 3 & 1.66 & 2.83 & 0.6303 & 3 \\
\hline NPD 4 & 1.55 & 2.93 & 0.6540 & 2 \\
\hline NPD 5 & 3.14 & 1.16 & 0.2698 & 5 \\
\hline
\end{tabular}

\section{Discussion}

In this section, smart product innovation and implications of the study are discussed to synthesize the insights generated for the future design and development of smart glasses. Overall speaking, this study presents a MCDM-based methodology to assist the NPD process from idea generation to the NPD project portfolio selection in a systematic manner. It was found that the project 'NPD 2' is the most approbative for the case company, where smart glasses should be equipped with functions of voice commands, 3D visualization, and phone calls. Finally, the proposed methodology can also be extended to other NPD projects to facilitate product innovation, in which design thinking, supply chain performance, and sustainability are balanced.

\subsection{Discussion on Smart Product Innovation}

In the contemporary product innovation process, design thinking is regarded as the sole design methodology to address ill-defined and uncertain design problems, while human needs can be effectively understood in order to reframe the design problems into a human-centric manner. With the aid of the proposed methodology, the entire product innovation process was revamped through the incorporation of multi-criteria decision-making approaches. For ideas at the brainstorming and market research stage, the Bayesian BWM was applied to provide group decision analysis for prioritization of weak promising product features on the market. Compared with the conventional product design process, such a systematic approach is helpful in analyzing a substantial amount of market information so as to define the problems and objectives for NPD in a human-centric manner. In fact, a number of NPD ideas can be generated through the above 'Empathize' and 'Define' stages. Although most new product innovation ideas on the market are attractive and can draw significant attention from customers, the supply chain capabilities that are essential in leading to product innovation success should be considered. To balance supply chain performance and sustainability, the proposed methodology incorporates the 
SustainableSCOR model into the NPD project portfolio selection process. Consequently, the most capable and sustainable NPD idea for specific case companies can be obtained when considering product testing and production. An overestimation of the company's capabilities can be avoided so as to eliminate the likelihood of NPD failures and supply chain disruption. Overall speaking, the proposed methodology complements the existing product innovation process under the design thinking framework so as to drive smart product innovation in the industry.

\subsection{Research and Industrial Implications}

Apart from complementing the existing product innovation process, this study also concentrates on the sustainability and human-centric innovation of NPD, which aligns with the vision of Industry 5.0 for the transition to a sustainable, human-centric, and resilient industry [29]. Beyond the digitalization advocated for in Industry 4.0, more considerations for people, society, and even the planet are focused on to drive societal goals. In the context of product innovation, NPD failures lead not only to the loss of business profits and reputation but also to the waste of resources, talent, and materials, which should be avoided in the industry. The deployment of the SustainableSCOR model in the product innovation process facilitates sustainable development for NPD as a constructive element in the era of circular manufacturing. More research and industrial opportunities can be opened up to establish more sustainable, human-centric, and resilient product innovation.

In regard to global electronic waste, an increasing trend was observed starting from 2010, and 53.6 million metric tons of global electronic waste was recorded in 2019 and increased by approximately $58.6 \%$ over the following decade [30]. It is foreseen that the growth of electronic waste worldwide is portentously rapid due to the launch of increasingly more advanced electronic devices on the market, such as smart glasses [31]. Typical design thinking that emphasizes customer centricity should further incorporate the concept of sustainability so as to drive for the eco-innovation of products and services. To achieve sustainable design thinking, this study explores the possibility of a sustainable design of smart glasses from the supply chain perspective based on the SustainableSCOR model such that selected NPD products through the proposed methodology outperform the rest in terms of reliability, responsiveness, agility, cost, assets, and sustainability. By doing so, sustainability from the supply chain perspective can be effectively considered in the product and service innovation process.

\section{Conclusions}

This study complements the existing product innovation process under the design thinking framework through the consideration of MCDM methods and the SustainableSCOR model. The MCDM methods play an essential role in prioritizing the emerging product features on the market and in ranking various NPD projects. Moreover, the core dimensions of the SustainableSCOR model are incorporated into the proposed methodology to balance supply chain performance and sustainability in the product innovation process. The proposed methodology was implemented in a case company to assist the NPD process for smart glasses, in which a focus group interview was undertaken to collect opinions and perspectives. It was found that voice command, 3D visualization, and phone call functions were the most important features in developing next-generation smart glasses. In addition, the two-stage methodology plays a role in assisting the NPD project selection process such that the perspectives of all decision makers are aggregated and analyzed to produce a final design decision. For future work, the proposed two-stage methodology can be extended to other NPD projects to investigate its effectiveness and performance. In addition, the impact on business sustainability and the environment can be measured through a longitudinal study. 
Author Contributions: Conceptualization, C.-K.-M.L., L.L. and Y.-P.T.; methodology, C.-K.-M.L. and L.L.; software, Y.-P.T.; formal analysis, C.-K.-M.L. and Y.-P.T.; data curation, C.-K.-M.L. and L.L.; writing—original draft preparation, C.-K.-M.L. and Y.-P.T.; writing—review and editing, C.-K.-M.L. and L.L.; supervision, C.-K.-M.L. All authors have read and agreed to the published version of the manuscript.

Funding: This research is funded by the Laboratory for Artificial Intelligence in Design (Project Code: RP2-2), Hong Kong Special Administrative Region.

Institutional Review Board Statement: Not applicable.

Informed Consent Statement: Not applicable.

Data Availability Statement: The data presented in this study are available on request from the corresponding author. The data are not publicly available due to confidentiality of the case company.

Acknowledgments: The authors would like to thank the Department of Industrial and Systems Engineering, The Hong Kong Polytechnic University, for supporting this research. This research is funded by the Laboratory for Artificial Intelligence in Design (Project Code: RP2-2), Hong Kong Special Administrative Region. Gratitude is extended to Innovation Technology Co., Ltd. for inspiring this research.

Conflicts of Interest: The authors declare no conflict of interest.

\section{Appendix A}

The specifications of the five NPD projects are described in this section to provide an overview of the smart glasses. The decision makers in the case company are required to select one of them as the target in its research and development team.

Table A1. Planned specifications of NPD 1.

\begin{tabular}{|c|c|}
\hline Attribute & Description \\
\hline Name & NPD 1 \\
\hline Weight & $\begin{array}{l}\text { Headset: } \sim 88 \text { g; computing unit: } \sim 140 \text { g; detachable } \\
\text { controller: } \sim 20 \text { g }\end{array}$ \\
\hline Camera & $\begin{array}{l}\text { 5MP RGB camera } \\
\text { SLAM camera }\end{array}$ \\
\hline Optics & Birdbath \\
\hline CPU & Qualcomm Snapdragon 845 \\
\hline Display resolution & $1980 \times 1020$ \\
\hline Storage & $128 \mathrm{~GB}$ \\
\hline Video Playback & 1080 \\
\hline OS & Android OS \\
\hline RAM & $8 \mathrm{~GB}$ \\
\hline Battery Capacity & $7100 \mathrm{mAh}$ \\
\hline Audio & $\begin{array}{l}\text { Dual speakers } \\
\text { Dual microphones }\end{array}$ \\
\hline Field of View & 52 degrees \\
\hline Degrees of Freedom (DoF) & $\begin{array}{l}\text { Headset: 6DoF } \\
\text { Controller: 3DoF }\end{array}$ \\
\hline Connectivity & USB Type-C \\
\hline Sensor & $\begin{array}{l}\text { IMU 9-axis (accelerometer/gyroscope) } \\
\text { Ambient light sensor } \\
\text { Proximity sensor }\end{array}$ \\
\hline
\end{tabular}


Table A2. Planned specifications of NPD 2.

\begin{tabular}{ll}
\hline Attribute & Description \\
\hline Name & NPD 2 \\
\hline Weight & $\sim 98 \mathrm{~g}$ \\
\hline Camera & $5 \mathrm{MP}$ RGB camera \\
\hline Optics & $5 \mathrm{MP}$ IR detector camera \\
\hline Display resolution & LCoS optical engine \\
\hline Video Playback & $1280 \times 720$ with dual see-through display \\
\hline \multirow{2}{*}{ Audio } & 1080 \\
\hline Field of View (FOV) & Built-in stereo speaker \\
\hline Connectivity & Built-in microphone \\
\hline \multirow{2}{*}{ Sensor } & 45 degrees \\
& USB-C (DisplayPort) \\
\hline
\end{tabular}

Table A3. Planned specifications of NPD 3.

\begin{tabular}{ll}
\hline Attribute & Description \\
\hline Name & NPD 3 \\
\hline Weight & $\sim 80$ g \\
\hline Camera & 8 MP RGB camera \\
\hline Optics & Waveguide \\
\hline CPU & Qualcomm Snapdragon 870 \\
\hline Display resolution & $1920 \times 1080$ \\
\hline Storage & 128 GB \\
\hline Video Playback & 1080 \\
\hline OS & iOS and Android \\
\hline RAM & 8 GB \\
\hline Battery Capacity & 8000 mAh \\
\hline Audio & Microphones \\
\hline Field of View & 90 degrees \\
\hline Degrees of Freedom (DoF) & 6 DoF \\
\hline Connectivity & USB Type-C \\
\hline Sensor & IMU 9-axis (accelerometer/magnetometer/gyroscope) \\
\hline
\end{tabular}


Table A4. Planned specifications of NPD 4.

\begin{tabular}{ll}
\hline Attribute & Description \\
\hline Name & NPD 4 \\
\hline Weight & $\sim 500 \mathrm{~g}$ \\
\hline Camera & $8 \mathrm{MP}$ camera and eye tracking \\
\hline Optics & Waveguide \\
\hline CPU & Qualcomm Snapdragon 850 \\
\hline Display resolution & $2048 \times 1080 ; 3 \mathrm{D}$ visualization \\
\hline Storage & 64 GB \\
\hline OS & Android \\
\hline Battery & 3 h of active use \\
\hline Audio & Microphones \\
\hline Field of View & 90 degrees \\
\hline Degrees of Freedom (DoF) & 6 DoF \\
\hline Connectivity & WIFI, Bluetooth \\
\hline Sensor & Accelerometer, gyroscope, magnetometer \\
\hline
\end{tabular}

Table A5. Planned specifications of NPD 5.

\begin{tabular}{ll}
\hline Attribute & Description \\
\hline Name & NPD 5 \\
\hline Weight & $\sim 40 \mathrm{~g}$ \\
\hline Camera & $/$ \\
\hline Optics & Anti-blue light lenses \\
\hline CPU & $/$ \\
\hline Display resolution & $/$ \\
\hline Storage & $/$ \\
\hline OS & iOS/Android \\
\hline Battery & 3 h of active use \\
\hline Audio & Whisper Audio with multi-microphones \\
\hline Field of View & $/$ \\
\hline Degrees of Freedom (DoF) & $/$ \\
\hline Connectivity & Bluetooth 5.0 BLE \\
\hline Sensor & 9 -axis full motion sensors \\
\hline
\end{tabular}

\section{References}

1. Dou, R.L.; Li, W.; Nan, G.F. An integrated approach for dynamic customer requirement identification for product development. Enterp. Inf. Syst. 2019, 13, 448-466. [CrossRef]

2. 10 Recent Product Design Failures and What We Can Learn from Them. Available online: https://www.forbes.com/sites/ blakemorgan/2019/09/09/10-recent-product-design-failures-and-what-we-can-learn-from-them/?sh=6763f81e46f1 (accessed on 14 December 2020).

3. How \& Why Google Glass Failed. Available online: https://www.investopedia.com/articles/investing/052115/how-whygoogle-glass-failed.asp (accessed on 7 April 2021).

4. Jeff Bezos to Exec after Product Totally Flopped: 'You Can't, for One Minute, FEEL BAD'. Available online: https:/ /www.cnbc com/2020/05/22/jeff-bezos-why-you-cant-feel-bad-about-failure.html (accessed on 7 April 2021). 
5. Facebook Home Is a Flop: Employees Know It and Users Don't Like It. Available online: https://www.businessinsider.com/ facebook-home-is-a-flop-2013-5 (accessed on 7 April 2021).

6. Schiffels, S.; Fliedner, T.; Kolisch, R. Human behavior in project portfolio selection: Insights from an experimental study. Decis. Sci. 2018, 49, 1061-1087. [CrossRef]

7. Ma, J.; Harstvedt, J.D.; Jaradat, R.; Smith, B. Sustainability driven multi-criteria project portfolio selection under uncertain decision-making environment. Comput. Ind. Eng. 2020, 140, 106236. [CrossRef]

8. Elsbach, K.D.; Stigliani, I. Design thinking and organizational culture: A review and framework for future research. J. Manag. 2018, 44, 2274-2306. [CrossRef]

9. Fargnoli, M.; Sakao, T. Uncovering differences and similarities among quality function deployment-based methods in Design for X: Benchmarking in different domains. Qual. Eng. 2017, 29, 690-712. [CrossRef]

10. Rihar, L.; Kušar, J. Implementing Concurrent Engineering and QFD Method to Achieve Realization of Sustainable Project. Sustainability 2021, 13, 1091. [CrossRef]

11. Salonitis, K. Design for additive manufacturing based on the axiomatic design method. Int. J. Adv. Manuf. Technol. 2016, 87, 989-996. [CrossRef]

12. Chakraborty, K.; Mondal, S.; Mukherjee, K. Analysis of product design characteristics for remanufacturing using Fuzzy AHP and Axiomatic Design. J. Eng. Des. 2017, 28, 338-368. [CrossRef]

13. Tsang, Y.P.; Wu, C.H.; Lin, K.Y.; Tse, Y.K.; Ho, G.T.S.; Lee, C.K.M. Unlocking the power of big data analytics in new product development: An intelligent product design framework in the furniture industry. J. Manuf. Syst. 2021. [CrossRef]

14. Zhang, M.; Zeng, W.; Tse, Y.K.; Wang, Y.; Smart, P. Examining the antecedents and consequences of green product innovation. Ind. Mark. Manag. 2021, 93, 413-427. [CrossRef]

15. Li, S.M.; Chan, F.T.S.; Tsang, Y.P.; Lam, H.Y. New Product Idea Selection in the Fuzzy Front End of Innovation: A Fuzzy Best-Worst Method and Group Decision-Making Process. Mathematics 2021, 9, 337. [CrossRef]

16. Costantino, F.; Di Gravio, G.; Nonino, F. Project selection in project portfolio management: An artificial neural network model based on critical success factors. Int. J. Proj. Manag. 2015, 33, 1744-1754. [CrossRef]

17. Wang, X.-Y.; Li, G.; Tu, J.-F.; Khuyen, N.T.T.; Chang, C.-Y. Sustainable Education Using New Communication Technology: Assessment with Analytical Hierarchy Process (AHP). Sustainability 2021, 13, 9640. [CrossRef]

18. Rezaei, J. Best-worst multi-criteria decision-making method. Omega-Int. J. Manag. Sci. 2015, 53, 49-57. [CrossRef]

19. Peng, C.; Feng, D.; Guo, S. Material Selection in Green Design: A Method Combining DEA and TOPSIS. Sustainability 2021, 13, 5497. [CrossRef]

20. Mohammadi, M.; Rezaei, J. Bayesian best-worst method: A probabilistic group decision making model. Omega-Int. J. Manag. Sci. 2020, 96, 102075. [CrossRef]

21. Palczewski, K.; Sałabun, W. The fuzzy TOPSIS applications in the last decade. Procedia Comput. Sci. 2019, 159, $2294-2303$. [CrossRef]

22. Daghfous, A.; Zoubi, T. An Auditing Framework for Knowledge-Enabled Supply Chain Management: Implications for Sustainability. Sustainability 2017, 9, 791. [CrossRef]

23. Rauschnabel, P.A.; Brem, A.; Ivens, B.S. Who will buy smart glasses? Empirical results of two pre-market-entry studies on the role of personality in individual awareness and intended adoption of Google Glass wearables. Comput. Hum. Behav. 2015, 49, 635-647. [CrossRef]

24. Schütze, S.; Irwin-Schütze, A. New Realities in Audio: A Practical Guide for VR, AR, MR and 360 Video; CRC Press: Boca Raton, FL, USA, 2018.

25. Cipresso, P.; Giglioli, I.A.C.; Raya, M.A.; Riva, G. The past, present, and future of virtual and augmented reality research: A network and cluster analysis of the literature. Front. Psychol. 2018, 9, 2086. [CrossRef]

26. Wolfartsberger, J. Analyzing the potential of Virtual Reality for engineering design review. Autom. Constr. 2019, 104, 27-37. [CrossRef]

27. Wiederhold, B.K.; Miller, I.T.; Wiederhold, M.D. Using virtual reality to mobilize health care: Mobile virtual reality technology for attenuation of anxiety and pain. IEEE Consum. Electron. Mag. 2017, 7, 106-109. [CrossRef]

28. Hu-Au, E.; Lee, J.J. Virtual reality in education: A tool for learning in the experience age. Int. J. Innov. Educ. Bus. 2017, 4, 215-226. [CrossRef]

29. Industry 5.0. Available online: https://ec.europa.eu/info/research-and-innovation/research-area/industrial-research-andinnovation/industry-50_en (accessed on 30 July 2021).

30. Electronic Waste Generated Worldwide from 2010 to 2019 (in Million Metric Tons). Available online: https:/ / www.statista.com/ statistics /499891/projection-ewaste-generation-worldwide/ (accessed on 8 September 2021).

31. Abalansa, S.; El Mahrad, B.; Icely, J.; Newton, A. Electronic Waste, an Environmental Problem Exported to Developing Countries: The GOOD, the BAD and the UGLY. Sustainability 2021, 13, 5302. [CrossRef] 